\title{
COLOR DOPPLER STUDY OF UTERINE AND UMBILICAL ARTERY IN NORMAL VS HYPERTENSIVE PREGNANT WOMEN AND ITS CORRELATION WITH FETAL OUTCOME
}

\author{
Sanjaya Sharma1, Sushila Kharakwal2, Vidya Chaudhary33, Seema ${ }^{4}$, Pratima 5 , Shashi ${ }^{6}$ \\ ${ }_{1}^{1}$ Professor \& HOD, Department of Obstetrics and Gynaecology, M. L. B. Medical College, Jhansi. \\ 2 Professor, Department of Obstetrics and Gynaecology, M. L. B. Medical College, Jhansi. \\ ${ }^{3}$ Associate Professor, Department of Obstetrics and Gynaecology, M. L. B. Medical College, Jhansi.

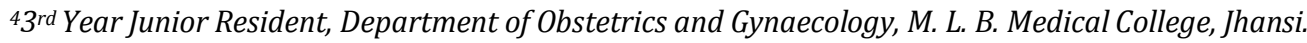 \\ 53rd Year Junior Resident, Department of Obstetrics and Gynaecology, M. L. B. Medical College, Jhansi. \\ 63rd Year Junior Resident, Department of Obstetrics and Gynaecology, M. L. B. Medical College, Jhansi.
}

\section{ABSTRACT}

\section{BACKGROUND}

Doppler sonography has become a part of routine antenatal surveillance in Obstetrics during past decade. Colour Doppler can be used to distinguish between low and high risk pregnancies.

\section{OBJECTIVES}

To analyze if colour Doppler can improve the clinical diagnosis and its effect on perinatal outcome.

\section{SELECTION CRITERIA}

All the patients enrolled are of reproductive age groups (15-45 yrs.) with any parity, gestational age of more than 28 weeks. We have divided the patients into 2 groups, one with blood pressure of $>140 / 90$ with proteinuria $>+1$, another with BP $<140 / 90$ and proteinuria $<+1$. All patients enrolled and Colour Doppler was done to study uterine artery and umbilical artery.

\section{RESULTS}

We did our colour Doppler study of umbilical arteries and both uterine arteries involving 200 patients and compared perinatal outcome in normotensives and hypertensives.

\section{CONCLUSION}

The use of utero-placental Doppler ultrasound improve pregnancy outcome by early diagnosis and early start of treatment.

\section{KEYWORDS}

Colour Doppler, SGA, AGA, IUGR.

HOW TO CITE THIS ARTICLE: Sharma S, Kharakwal S, Chaudhary V, et al. Color Doppler study of uterine and umbilical artery in normal vs hypertensive pregnant women and its correlation with fetal outcome. J. Evolution Med. Dent. Sci. 2016;5(15):685-687, DOI: $10.14260 /$ jemds/2016/158

\section{INTRODUCTION}

Doppler sonography in conjunction with 2D sonography has become an important tool in antenatal surveillance in Obstetrics. Blood flow velocimetry is done to look for any hemodynamic changes in uteroplacental and fetal vessels. These changes can be demonstrated well before clinical manifestation of obstetrics complications. Most commonly Doppler is done on uterine and umbilical arteries. Hypertensive disorders of pregnancy are found in $5-15 \%$ of pregnant patient. The utero-placental blood flow has been found to be decreased and resistance increased in hypertensive pregnancies and fetal growth restriction in comparison of normotensive pregnant patients, which are having low resistance and high blood flow.

Indices have been developed to measure the level of resistance like S/D ratio, pulsatility index and resistance index.

So in antenatal period, every hypertensive pregnant women should have colour Doppler to identify the

Financial or Other, Competing Interest: None.

Submission 03-01-2016, Peer Review 02-02-2016,

Acceptance 08-02-2016, Published 19-02-2016.

Corresponding Author:

Dr. Sanjaya Sharma,

Department of Obstetrics and Gynaecology,

M. L. B. Medical College, Jhansi.

E-mail: drsanjayasharma74@gmail.com

DOI: $10.14260 /$ jemds $/ 2016 / 158$ compromised and growth restricted fetus. ${ }^{1}$ The umbilical and uterine Doppler abnormalities have been documented in pregnancy complicated by hypertension and fetal growth restriction. ${ }^{2}$ Timely interventions can be done to improve maternal and fetal mortality and morbidity. Thus, the Doppler velocimetry has become an important tool in the evaluation and management of high-risk pregnancies. ${ }^{2}$

The study was conducted with the aims and objectives to study the Doppler velocimetric indices of the uterine and umbilical artery in normotensive and hypertensive pregnancy in the third trimester; to detect the number of small for gestational age fetuses with abnormal velocimetric study in each group and correlate the relation of birth weight and Doppler velocimetric findings with perinatal outcome in both the groups.

\section{AIMS AND OBJECTIVES}

To analyze blood flow velocity waveforms and numerical indices describing wave forms and to distinguish low and high risk pregnancies by uterine arteries and umbilical Doppler measurement.

\section{MATERIAL AND METHODS}

The present study was conducted in the Department of Obstetrics and Gynaecology, MLB Medical College Jhansi, during the period of 2 years, i.e. Aug 2013 to Sept 2015. A total of 200 cases from the women attending the antenatal 
outpatient department were included in the study of which 100 were hypertensive and 100 normotensive. All the women had a singleton pregnancy of $>32$ weeks/gestation and vertex presentation and did not have any history of medical disorder. Both primigravida and multigravida were selected for the study.

Among the hypertensive group, the women who had recorded blood pressure of $>140 / 90$ on two or more occasions six hours apart after adequate rest were selected. Baseline investigations and Doppler velocimetry of both the uterine arteries and umbilical artery was performed in both the groups. The patients were followed up till delivery. Antihypertensive medications like methyldopa, labetalol and nifedipine were given study group and blood pressure was maintained below $140 / 90 \mathrm{mmHg}$. Perinatal outcome in form of small for gestation age, neonatal death, intrauterine death, NICU admission and stay, Healthy were noted and compared with the results of the Systolic Diastolic (SD) ratio, Resistance Index (RI) and Pulsatility Index (PI) of Doppler velocimetry of uterine and umbilical artery.

\section{OBSERVATIONS}

The mean values of Uterine Artery Doppler Velocimetric Indices, i.e. S/D ratio, RI and PI (Table I) were higher in the hypertensive cases than normotensive cases of the same gestational age. The values in both the groups gradually decreased with increase in the gestational age. The mean SD ratio decreased from 4.72 at 28 weeks to 3.6 at $38-40$ weeks in the hypertensive group and from 3.11 at 28 weeks to 2.2 at 38 weeks in the normotensive group.

\begin{tabular}{|c|c|c|c|c|c|c|}
\hline & \multicolumn{3}{|c|}{ Normotensive } & \multicolumn{3}{c|}{ Hypertensive } \\
\hline $\begin{array}{c}\text { GESTATIONAL } \\
\text { AGE (IN WEEKS) }\end{array}$ & S/D & RI & PI & S/D & RI & PI \\
\hline$<28$ WEEKS & 3.11 & .73 & .96 & 4.72 & .9 & 1.5 \\
\hline $28-30$ WEEKS & 2.93 & .695 & .96 & 4.8 & 1.4 & 1.2 \\
\hline $30-32$ WEEKS & 2.8 & .67 & .88 & 3.8 & .9 & 1.4 \\
\hline $32-34$ WEEKS & 2.71 & .63 & .83 & 3.9 & 1.1 & 1.3 \\
\hline $34-36$ WEEKS & 2.45 & .57 & .78 & 3.6 & .8 & 1.2 \\
\hline $36-38$ WEEKS & 2.2 & .49 & .71 & 4 & 1.3 & 1.4 \\
\hline \multicolumn{6}{|c|}{ Table 1: The mean value of Doppler } \\
indices in uterine artery \\
\hline
\end{tabular}

The mean values of Umbilical Artery Doppler Velocimetric Indices (Table II) were higher in hypertensive than in normotensive group of the same gestation. The values in both the groups gradually decreased with increase in gestation. The mean SD ratio decreased from 4.72 at 28 weeks to 3.2 at 38-40 weeks in the hypertensive group and from 3.14 at 28 weeks to 2.2 at 38 weeks in the normotensive group.

\begin{tabular}{|c|c|c|c|c|c|c|}
\hline & \multicolumn{3}{|c|}{ Normotensive } & \multicolumn{2}{c|}{ Hypertensive } \\
\hline $\begin{array}{c}\text { GESTATIONAL } \\
\text { AGE (IN } \\
\text { WEEKS) }\end{array}$ & S/D & RI & PI & S/D & RI & PI \\
\hline$<28$ WEEKS & 3.14 & .747 & 1.07 & 4.73 & .95 & 1.3 \\
\hline $28-30$ WEEKS & 2.94 & .70 & .967 & 4.85 & 1.42 & 1.5 \\
\hline $30-32$ WEEKS & 2.8 & .69 & .896 & 3.8 & .9 & 1.2 \\
\hline $32-34$ WEEKS & 2.7 & .64 & .838 & 3.9 & 1.2 & 1.3 \\
\hline $34-36$ WEEKS & 2.4 & .58 & .79 & 3.2 & 1.34 & 1.2 \\
\hline 36-38 WEEKS & 2.2 & .52 & .72 & 4.26 & .9 & 1.5 \\
\hline Table 2: The mean value of Doppler indices in umbilical \\
artery \\
\hline \multicolumn{7}{|c|}{}
\end{tabular}

The result of Doppler findings of study and control group in association of appropriate and small for gestational age were statistically significant $(\mathrm{p}$ value $=$ 0.020) (Table III).

\begin{tabular}{|c|c|c|c|c|c|c|}
\hline $\begin{array}{l}\text { Uterine } \\
\text { artery }\end{array}$ & \multicolumn{3}{|c|}{ Control Group } & \multicolumn{3}{|c|}{ Study Group } \\
\hline & $\begin{array}{l}\text { SGA } \\
(\%)\end{array}$ & $\begin{array}{l}\text { AGA } \\
(\%)\end{array}$ & $\begin{array}{c}\text { Total } \\
(\%)\end{array}$ & $\begin{array}{l}\text { SGA } \\
(\%)\end{array}$ & $\begin{array}{l}\text { AGA } \\
(\%)\end{array}$ & $\begin{array}{l}\text { Total } \\
(\%)\end{array}$ \\
\hline Abnormal & 8 & 4 & 12 & 39 & 17 & 56 \\
\hline Normal & 18 & 70 & 88 & 11 & 33 & 44 \\
\hline Total & 26 & 74 & 100 & 50 & 50 & 100 \\
\hline $\begin{array}{l}\text { Umbilical } \\
\text { artery }\end{array}$ & \multicolumn{3}{|c|}{ Control Group } & \multicolumn{3}{|c|}{ Study Group } \\
\hline $\begin{array}{l}\text { Doppler } \\
\text { finding }\end{array}$ & $\begin{array}{l}\text { SGA } \\
(\%)\end{array}$ & $\begin{array}{l}\text { AGA } \\
(\%)\end{array}$ & $\begin{array}{l}\text { Total } \\
(\%)\end{array}$ & $\begin{array}{l}\text { SGA } \\
(\%)\end{array}$ & $\begin{array}{l}\text { AGA } \\
(\%)\end{array}$ & $\begin{array}{l}\text { Total } \\
(\%)\end{array}$ \\
\hline Abnormal & 9 & 7 & 16 & 26 & 13 & 39 \\
\hline Normal & 13 & 71 & 84 & 12 & 49 & 61 \\
\hline Total & 22 & 78 & 100 & 38 & 62 & 100 \\
\hline \multicolumn{7}{|c|}{$\begin{array}{l}\text { Table 3: Doppler findings among } \\
\text { controls and study group }\end{array}$} \\
\hline
\end{tabular}

In study group, uterine artery colour Doppler showed that $44 \%$ were having adverse perinatal outcome in which $9 \%$ were IUD, $4 \%$ neonatal death and $31 \%$ were NICU admissions. The data was statistically significant with Chi square valve 22.321 and $p$ value 0.00000231 . (Table 4).

Similarly, umbilical artery colour Doppler in study group showed $43 \%$ were having adverse perinatal outcome, in which $7 \%$ were IUD, $13 \%$ neonatal death and $29 \%$ were NICU admissions. The data was statistically significant with Yates Chi square valve 23.337 and $p$ value 0.00000136 . (Table IV).

\begin{tabular}{|c|c|c|c|c|c|c|c|}
\hline \multirow{2}{*}{$\begin{array}{c}\text { Birth } \\
\text { Weight }\end{array}$} & \multicolumn{3}{|c|}{$\begin{array}{c}\text { UTERINE } \\
\text { ARTERY } \\
\text { DOPPLER }\end{array}$} & \multicolumn{3}{c|}{$\begin{array}{c}\text { UMBILICAL } \\
\text { ARTERY } \\
\text { DOPPLER }\end{array}$} \\
\cline { 3 - 8 } & & N & Ab. & Total & N & Ab. & Total \\
\hline \multirow{2}{*}{ IUD } & AGA & 0 & 2 & 2 & 0 & 1 & 1 \\
\cline { 2 - 8 } & SGA & 0 & 7 & 7 & 0 & 6 & 6 \\
\hline & Total & 0 & 9 & 9 & 0 & 7 & 7 \\
\hline \multirow{2}{*}{ NND } & AGA & 0 & 1 & 1 & 1 & 2 & 3 \\
\cline { 2 - 8 } & SGA & 0 & 3 & 3 & 0 & 4 & 4 \\
\hline & Total & 0 & 4 & 4 & 1 & 6 & 7 \\
\hline \multirow{2}{*}{ NICU } & AGA & 5 & 9 & 14 & 8 & 5 & 13 \\
\cline { 2 - 8 } & SGA & 2 & 15 & 17 & 5 & 11 & 16 \\
\hline & Total & 7 & 24 & 31 & 13 & 16 & 29 \\
\hline \multirow{2}{*}{ Healthy } & AGA & 25 & 7 & 32 & 40 & 5 & 45 \\
\cline { 2 - 8 } & SGA & 5 & 19 & 24 & 7 & 5 & 12 \\
\hline & Total & 30 & 26 & 56 & 47 & 10 & 57 \\
\hline
\end{tabular}

Table 4: Perinatal outcome and Doppler study in hypertensives (Study group)

In control group, uterine artery colour Doppler showed only $11 \%$ were all having adverse perinatal outcome in which $4 \%$ neonatal death and $7 \%$ were NICU admissions, while umbilical artery colour Doppler showed $12 \%$ were all having adverse perinatal outcome in which $5 \%$ neonatal death and 9\% were NICU admissions. (Table V). 


\begin{tabular}{|c|c|c|c|c|c|c|c|}
\hline \multirow{2}{*}{ Outcome } & \multirow{2}{*}{$\begin{array}{c}\text { Birth } \\
\text { Weight }\end{array}$} & \multicolumn{3}{|c|}{ Uterine } & \multicolumn{3}{|c|}{ Umbilical } \\
\hline & & $\mathbf{N}$ & Ab. & Total & $\mathbf{N}$ & Ab. & Total \\
\hline \multirow{3}{*}{ NND } & AGA & 1 & 0 & 1 & 1 & 0 & 1 \\
\hline & SGA & 2 & 1 & 3 & 1 & 3 & 4 \\
\hline & Total & 3 & 1 & 4 & 2 & 3 & 5 \\
\hline \multirow{3}{*}{ NICU } & AGA & 3 & 1 & 4 & 1 & 2 & 3 \\
\hline & SGA & 3 & 0 & 3 & 2 & 4 & 6 \\
\hline & Total & 6 & 1 & 7 & 3 & 6 & 9 \\
\hline \multirow{3}{*}{ Healthy } & AGA & 75 & 2 & 77 & 71 & 6 & 77 \\
\hline & SGA & 12 & 0 & 12 & 6 & 5 & 11 \\
\hline & Total & 87 & 2 & 89 & 77 & 11 & 88 \\
\hline
\end{tabular}

\section{DISCUSSION}

The study shows major colour Doppler changes in umbilical and uterine arteries of hypertensive pregnant women compared to normotensives. In normal pregnancy, there is progressive fall in the uterine artery S/D ratio, pulsatility index and resistance index from second trimester till term. ${ }^{3}$ In hypertensive disorders of pregnancies, Doppler indices are higher. 4 The mean SD ratio decreased from 4.72 at 28 weeks to 3.6 at $38-40$ weeks in the hypertensive group and from 3.11 at 28 weeks to 2.2 at $38-40$ weeks in the normotensive group. Schulman et al. reported progressive fall in $\mathrm{s} / \mathrm{d}$ ratio with advancing gestational age. ${ }^{5}$

Correlation of perinatal outcome birth weight and Doppler findings in hypertensive and normotensive group. Jain et al. noted adverse perinatal outcome in $70 \%$ considering UA Doppler alone in high risk pregnancy. Abnormal uterine artery Doppler findings were found in $44 \%$ hypertensive and $11 \%$ normotensive cases. Abnormal umbilical artery Doppler waveforms were found in higher number of hypertensive as compared to normotensive cases ( $43 \%$ vs. $12 \%$ ). Trudinger et al. (1985) reported $47.3 \%$ cases of abnormal uterine artery Doppler in the study of hypertensive cases. ${ }^{6}$ The findings of the present study are more or less similar to those of Ducey et al. and others. Abnormal umbilical artery Doppler findings were seen more in hypertensive than normotensive cases (39\% vs. 19\%).

Thus in cases of hypertensive pregnant women with abnormal and normal colour Doppler finding, we can arrest the changes by appropriate therapy and decrease the maternal and perinatal morbidity and mortality.
Management includes close monitoring of maternal and fetal wellbeing, tight control of hypertension, corticosteroid therapy in preterm. First line antihypertensive drugs include methyldopa, labetalol. Second line agents are hydralazine, nifedipine and prazosin. ${ }^{7}$

\section{CONCLUSIONS}

Colour Doppler is a very important diagnostic tool to screen high risk among hypertensive pregnant women. It helps in screening the patients who need strict monitoring for their fetal well-being. Our study shows that Abnormal Doppler findings of the uterine and umbilical are more common in SGA fetuses. By detecting decreased uteroplacental and fetoplacental blood flow, it can identify an hypoxic fetus. ${ }^{6}$ and we can do timely interventions and decrease perinatal mortality and morbidity to an extent. So colour Doppler should be performed as a routine test in hypertensive pregnant women.

\section{REFERENCES}

1. Cunningham FG, Leveno KJ. Pregnancy hypertension. Williams textbook of Obstetrics. New York: McGraw Hill Medical Publishing Division; 2010;705-756.

2. Bulletins--Obstetrics ACoP. ACOG practice bulletin. Diagnosis and management of pre-eclampsia and eclampsia. Number 33, January 2002. Obstetrics and Gynecology. 2002;99(1):159-67.

3. Trudinger BJ. The principles and practice of ultrasonography in Obs and Gynecology. 4th edition; Obstetrics Doppler application: 12:173.

4. Joern H and Rath W. Comparison of Doppler sonographic examinations of the umbilical and uterine arteries in high-risk pregnancies. Fetal Diagnosis and Therapy, 13, 150-153. doi:10.1159/000020827.

5. Farmakides G, Schulman H, Schneider E. Surveillance of pregnant hypertensive patient with Doppler flow velocimetry. Clinical Obstetrics and Gynecology Vol. 35, No.2, June 1992;387-394.

6. Trudinger BJ, Cook CM, et al. Fetal umbilical artery velocity waveforms and subsequent neonatal outcome. Br J Obstetric Gynecology 1985;98:378-384.

7. Giles WB, Trudinger BJ, Baird PJ. Fetal umbilical artery flow velocity waveforms and placental resistance: pathological correlation. Br J Obstetric Gynaecology 1985;92:31-8. 